\title{
Desempenho e emissões de um motor-gerador ciclo diesel sob diferentes concentrações de biodiesel de soja
}

\author{
Elton F. dos Reis', João P. B. Cunha' ${ }^{2}$, Diego L. S. Mateus ${ }^{1}$, \\ Josué G. Delmond ${ }^{3}$ \& Ródney F. Couto ${ }^{1}$
}

\begin{abstract}
RESUMO
No cenário atual brasileiro de constantes quedas de energia e iminência de uma crise no setor elétrico, a utilização de grupos geradores tem sido bastante comum no meio rural e os bicombustíveis, como o biodiesel, representam uma opção para diversificação da matriz energética. Este trabalho objetivou avaliar o uso do biodiesel de soja em diferentes concentrações em um motor de ciclo diesel sob diferentes demandas de cargas do motor. Foram utilizadas as concentrações: $5 \%$ (B5), 10\% (B10), 20\% (B20), 50\% (B50), $75 \%$ (B75) e 100\% de biodiesel (B100) em um grupo gerador a diesel, com motor de $5 \mathrm{Hp}$ de quatro tempos, em diferentes condições de operação do motor, por meio de demandas de cargas elétricas: $500,1.000,1.500,2.000 \mathrm{~W}$ e desligadas conectadas ao grupo gerador. Foram realizados ensaios para quantificação do consumo horário de combustível e da emissão de gases. As variáveis sofreram influência significativa conforme foram alteradas as cargas elétricas e as misturas de combustível. O uso do biodiesel em concentrações maiores reduz consideravelmente a emissão da maioria dos gases poluentes e se tem praticamente anulada a emissão de enxofre para concentrações acima de $65 \%$ de biodiesel.
\end{abstract}

Palavras-chave: biocombustíveis, geração de energia, eficiência energética, gases estufa

\section{Performance and emissions of a diesel engine-generator cycle under different concentrations of soybean biodiesel}

\begin{abstract}
In the current scenario of constant power drops in Brazil and an imminent crisis in the electricity sector, the use of generators and biofuels such as biodiesel has been quite common in rural areas represents an option for diversification of the energy matrix. This study evaluated the use of soybean biodiesel in different concentrations in a diesel engine cycle under different demands of engine loads. Concentrations used were: $5 \%$ (B5), 10\% (B10), 20\% (B20), 50\% (B50), 75\% (B75) and 100\% biodiesel (B100) in a diesel generator with engine of $5 \mathrm{Hp}$ of four-stroke under different operating conditions of the engine, through the demands of electrical loads: 500, 1.000, 1.500, $2.000 \mathrm{~W}$ and off connected to the generator. Tests were conducted to quantify the hourly consumption of fuel and gas emissions. The variables suffered significant influence as the electrical charges and fuel mixtures were changed. The use of biodiesel in higher concentrations considerably reduces the emission of majority of pollutant gases and practically nullified the emission of sulfur in concentrations above $65 \%$ biodiesel.
\end{abstract}

Key words: biofuels, energy generation, energy efficiency, greenhouse gases

' Universidade Estadual de Goiás - Campus Henrique Santillo, BR 153, n. 3.105 - Fazenda Barreiro do Meio, CEP 75132-903, Anápolis, GO. Fone: (62) 3328-1156. E-mail: fialhoreis@ueg.br; eng.1995@bol.com.br; rodneycouto@agricola.eng.br

2 DEG/UFLA, Campus Universitário, CEP 37200-000, Lavras, MG. Fone: (35) 3829-1481. E-mail: bcunha_2@hotmail.com

${ }^{3}$ Universidade Estadual de Goiás - UnU Santa Helena, Via Protestato Joaquim Bueno, n. 945 - Perímetro Urbano, CEP 75920-000, Santa Helena de Goiás, GO. Fone: (64) 3641-3053; E-mail: josuegd@gmail.com.br 


\section{INTRODUÇÃO}

A expectativa de crise no setor elétrico brasileiro é crescente visto que os investimentos governamentais e privados não acompanham o aumento da demanda, que é crescente e irregular, sobretudo no meio rural.

Castellanelli et al. (2007) ressaltam que, com o regime atual de tarifas, os produtores rurais optam pela contratação do fornecimento de energia elétrica pelo regime de tarifas especiais e/ou utilizam grupos geradores para o suprimento de energia elétrica nos horários de ponta reduzindo, então, os custos do consumo de energia elétrica.

Desta forma, a autoprodução representa uma opção para os consumidores que procuram uma alternativa para redução de suas tarifas e vêem nela a possibilidade de gerar sua própria energia elétrica a partir de fontes descentralizadas de energia, a exemplo do diesel, biodiesel e gás natural.

Ramos et al. (2003) citam que vários estudos têm mostrado e ratificado a importância do uso da biomassa como fonte de energia. Segundo Romero \& Miralles (2002) o uso de óleos vegetais transesterificados (biodiesel) em substituição ao óleo diesel de petróleo promove redução das emissões de poluentes a concentração da mesma na atmosfera, visto que a ausência de enxofre em sua composição reduz a emissão de gases de enxofre, material particulado e hidrocarbonetos não queimados.

Atualmente, a possibilidade que mais se utiliza no Brasil é a de culturas já estabelecidas comercialmente, como a soja, que apresenta condições edafoclimáticas as quais possibilitam sua exploração na maioria das regiões do País quando comparada a outras oleaginosas. Segundo Peres \& Beldrano (2006) a soja pode ser considerada a cultura que permitiu a abertura do mercado de biocombustíveis baseados em óleos vegetais possibilitando a inserção de produtos com maior eficiência energética, como o caso do girassol e da canola.

Nos últimos 250 anos as concentrações de alguns gases, como o dióxido de carbono, aumentaram a níveis críticos. Desta maneira, $75 \%$ dos gases emitidos são oriundos da queima de combustível. Segundo Miragaya (2005) as emissões dos motores a diesel estão diretamente relacionadas com a qualidade de queima obtida, em que é cada vez mais importante a realização de estudos para melhor compreensão deste processo, como um todo.

Diversos pesquisadores vêm estudando o efeito da utilização de biodiesel em motores geradores. Silva et al. (2012) verificaram, analisando o desempenho de conjunto motor gerador utilizando quatro proporções volumétricas de biodiesel da gordura de frango e comparando-as às do óleo diesel mineral, que o desempenho do conjunto motor gerador foi superior quando acionado a óleo diesel; no entanto, a proporção com $20 \%$ de biodiesel no combustível substitui parcialmente o óleo diesel, sem perdas significativas das variáveis analisadas.

Já Penteado et al. (2007) verificaram, avaliando as emissões em um motor gerador alimentado com biodiesel de soja (B 100) e diesel convencional, que utilizando B100 houve redução de $\mathrm{CO}, \mathrm{HC}$ e fuligem, porém ocorreu, neste caso, maior emissão de NOx. Com relação ao teste de durabilidade, com o aumento da potência requerida pelo motor o funcionamento com o diesel e o B100 mostrou-se semelhante.
Assim, o objetivo do presente trabalho foi avaliar alguns parâmetros de desempenho e de emissões gasosas em um grupo gerador a diesel, submetido a diferentes combinações de concentrações de biodiesel de soja e cargas resistivas.

\section{Material e Métodos}

O presente estudo foi conduzido na Universidade Estadual de Goiás, Unidade Universitária de Ciências Exatas e Tecnológicas, na área externa do laboratório de Protótipos de Máquinas do Departamento de Engenharia Agrícola, em Anápolis, Goiás.

Foram utilizados delineamento experimental inteiramente casualizado, no esquema fatorial $5 \times 6$, cinco demandas de carga elétrica pelo gerador $(0,500,1.000,1.500$ e $2.000 \mathrm{~W})$ e seis concentrações de combustíveis (B5, B10, B25, B50, B75 e B100) com três repetições.

Nos ensaios utilizou-se um grupo gerador de ciclo Diesel, da marca Branco, Modelo BD2500CF, com motor mono-cilindro, quatro tempos, com potência nominal de $3,73 \mathrm{~kW}(5$ Hp) e capacidade nominal do gerador de $2,2 \mathrm{~kW}$. De acordo com recomendações do fabricante, ao se dar início ao funcionamento do grupo gerador foi necessário deixá-lo ligado em funcionamento por cerca de cinco minutos, sem carga, para que a temperatura do carter estabilizasse; desta forma, antes de ser iniciado o experimento e em cada sequência de ensaios, seguiuse tal recomendação para que a temperatura de funcionamento do motor não influenciasse nos resultados obtidos.

Quando necessária a troca de combustível, o motor permaneceu ligado consumindo $50 \mathrm{~mL}$ da nova mistura antes de quantificar as variáveis em análise procedimento que serviu para a adaptação do sistema de alimentação do motor e para a eliminação do combustível anterior.

Como componente nas misturas estudadas no ensaio, foi utilizado óleo diesel interior proveniente de uma mesma batelada, o qual contava com $5 \%$ de biodiesel, de acordo com a legislação em vigor. Já o biodiesel de soja utilizado nos ensaios foi fornecido por uma empresa comercial produtora deste tipo de combustível, localizada no município de Anápolis, GO. Desta forma, todas as misturas ensaiadas estavam em conformidade com as especificações em vigor (Brasil, 2008).

Para simular as cargas demandadas foram conectadas lâmpadas incandescentes associadas em paralelo, correspondentes às cargas 500, $1.000,1.500$ e $2.000 \mathrm{~W}$ e sem carga $(0 \mathrm{~W})$ as quais foram controladas por quatro interruptores, conforme Figura 1A, permitindo avaliar o comportamento do motor em diferentes condições de trabalho do grupo gerador.

O consumo das diferentes misturas avaliadas foi obtido por meio de um medidor volumétrico, como descrito por Barbosa et al. (2008), constituído por uma bureta graduada acoplada ao bico injetor por meio de uma mangueira, conforme a Figura 1B. O tempo de realização de cada teste foi contabilizado com um cronômetro digital obtendo-se, daí, o consumo horário de combustível. Desta maneira, a Eq. 1 mostra o cálculo do consumo de combustível realizado em cada um dos testes de desempenho do conjunto. 
A.

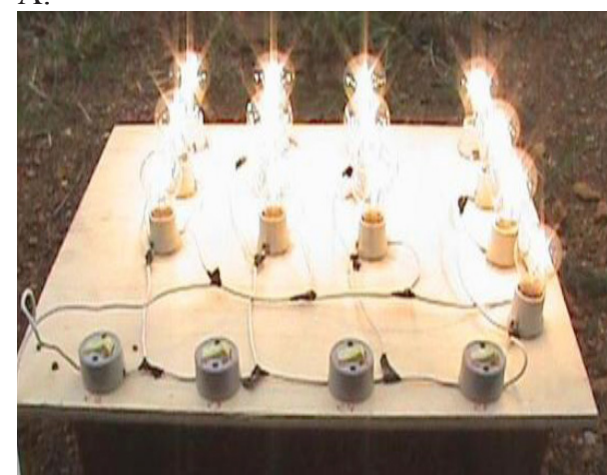

B.
C.

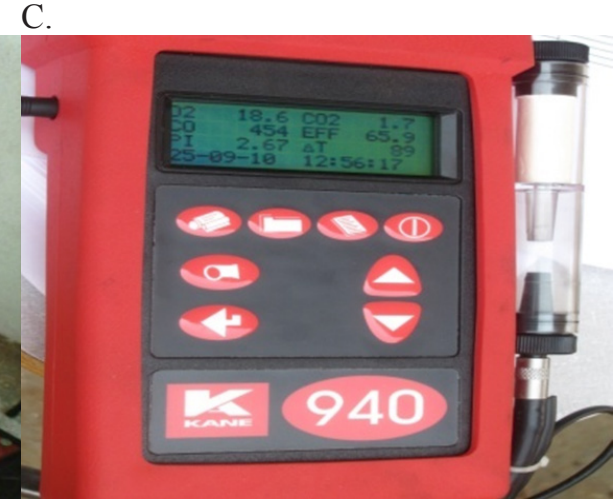

Figura 1. Ensaio do grupo gerador: cargas acopladas (A); medição do consumo de combustível (B) e monitor ambiental para a medição da emissão de gases (C)

$$
\mathrm{Chv}=\frac{3,6 \mathrm{C}}{\mathrm{t}}
$$

em que:

Chv - consumo horário volumétrico, $\mathrm{L} \mathrm{h}^{-1}$

C - volume consumido, $30 \mathrm{~mL}$

t $\quad$ - tempo gasto em cada ensaio, $h$

Visando à medição dos níveis de gases emitidos pelo motor, foi utilizado um monitor ambiental modelo 940, da marca KANE, conforme Figura 1C, acoplado ao sistema de exaustão do motor gerador. $\mathrm{O}$ equipamento permitiu a aquisição e a análise de sete parâmetros $\left(\mathrm{O}_{2}, \mathrm{CO}, \mathrm{CO}_{2}\right.$, $\mathrm{NO}_{x}, \mathrm{SO}_{2}$, temperatura dos gases de combustão e eficiência de combustão). O estudo desses parâmetros possibilita uma compreensão melhor do processo de combustão explicando as influências do combustível quando se utilizam as diferentes misturas de diesel/biodiesel de soja.

Os dados obtidos foram tabulados e submetidos à análise de variância pelo teste de $\mathrm{F}$ a 5\% de probabilidade e analisados por meio de análise de regressão ou superfície de resposta, quando significativos.

\section{Resultados E Discussão}

A análise de variância demonstrou que a interação entre as cargas aplicadas e o tipo de combustível influenciou significativamente nas seguintes variáveis: consumo horário, dióxido de carbono $\left(\mathrm{CO}_{2}\right)$, óxido de nitrogênio ( $\mathrm{NOx}$ ), dióxido de enxofre $\left(\mathrm{SO}_{2}\right)$, eficiência de combustão, temperatura dos gases de escape e oxigênio $\left(\mathrm{O}_{2}\right)$. Para as emissões de monóxido de carbono $(\mathrm{CO})$ a interação entre os fatores não foi significativa; todavia, constatou-se efeito das cargas e do tipo de combustível na emissão de CO quando esses fatores foram analisados de forma isolada.

Houve variação do consumo horário de combustível em função das diferentes cargas aplicadas e diferentes percentuais de mistura de biodiesel em que a equação gerada apresentouse altamente significativa mostrando que o modelo é capaz de explicar as variações dos dados experimentais.

A partir do modelo apresentado na Figura 2 foi gerada a superfície de resposta do consumo horário de combustível em função da carga do grupo gerador e dos diferentes percentuais de biodiesel adicionado ao óleo diesel. Comportamento semelhante foi observado por Soranso et al. (2008) os quais verificaram que, com o aumento das porcentagens de biodiesel na mistura, ocorreu aumento do consumo horário apresentando, assim, desempenho inferior em relação ao diesel interior (B5).

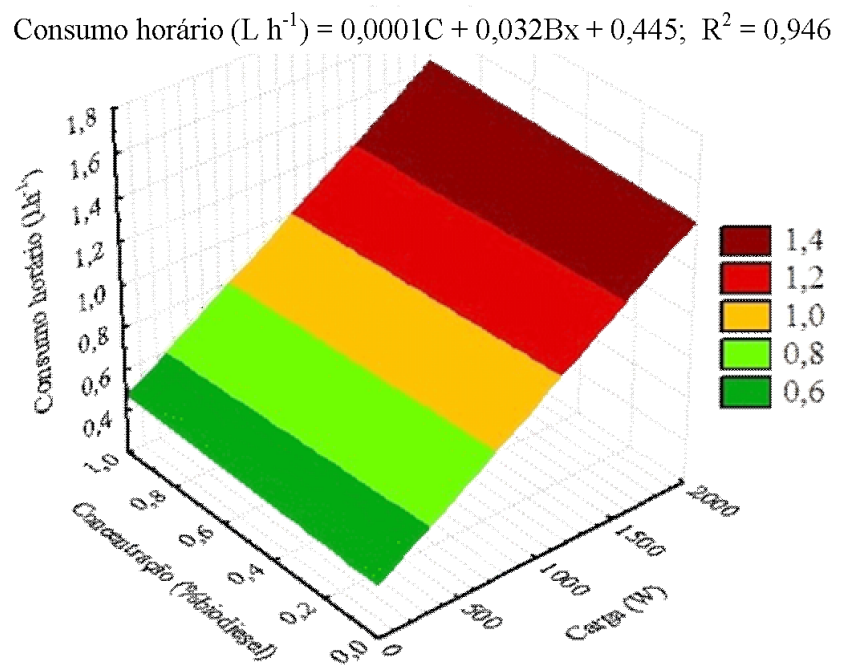

Figura 2. Consumo de combustível em função da carga e da concentração de biodiesel

A diferença de consumo era esperada, pelo fato do biodiesel puro (B100) possuir menor poder calorífico em relação ao diesel interior (B5), conforme Castellanelli et al. (2008). Além disto, Msipa et al. (1983) e Xue et al. (2011) apontam a tensão superficial, a viscosidade e a densidade como parâmetros críticos na previsão de haver ou não atomização apropriada para determinado combustível, o que determina a facilidade de carburação.

$\mathrm{Na}$ avaliação dos gases emitidos pelos diferentes percentuais de biodiesel e cargas solicitadas no grupo gerador observou-se que as emissões de oxigênio aumentaram com a elevação da concentração de biodiesel; em contrapartida, ocorreu diminuição com o aumento da carga aplicada, conforme Figura 3.

Segundo Correa et al. (2008), a maior quantidade de cadeias oxigenadas presentes no biodiesel contribui para a emissão do gás oxigênio em comparação com o diesel mineral. Para Grabosky \& Mccormick (1998), este aumento permite uma queima melhor do combustível, reduzindo a 
$\mathrm{O}_{2}(\%)=-0,01 \mathrm{C}+0,3791 \mathrm{Bx}+18,897 ; \mathrm{R}^{2}=0,898$

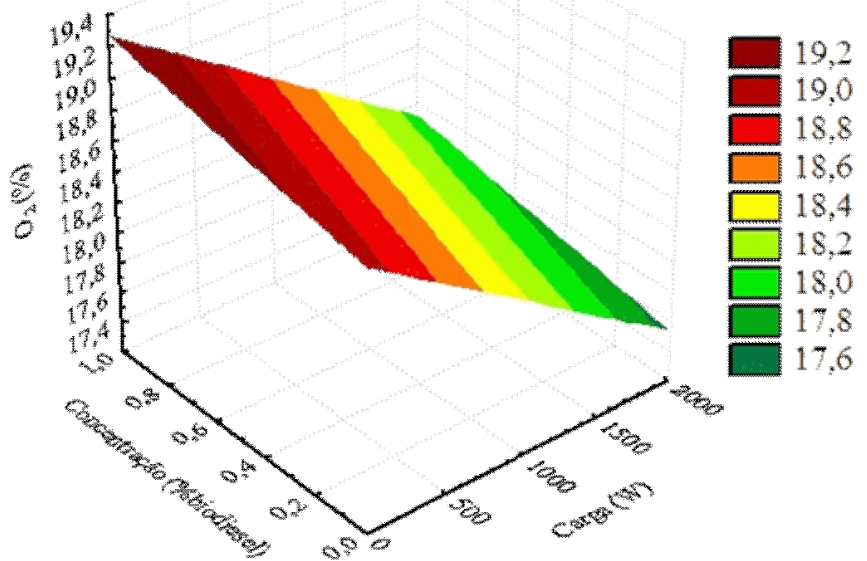

Figura 3. Emissão de oxigênio em função da carga e da concentração de biodiesel

formação de material particulado na câmara de combustão, o que se caracteriza como uma vantagem do uso de maiores percentuais de biodiesel na mistura.

De acordo com a Figura 4A, pode-se verificar o efeito do aumento da carga aplicada no sistema, nas emissões de monóxido de carbono. É possível observar que o aumento da carga aplicada no sistema até a potência de $1.500 \mathrm{~W}$ promoveu pontos de redução na emissão de monóxido de carbono. Entretanto, quando atingida a potência de $2.000 \mathrm{~W}$ os valores de emissão aumentaram significativamente em $25,2 \%$. Segundo Silva et al. (2003) este fato pode ter ocorrido devido à queda na eficiência de combustão com o aumento da concentração de biodiesel ocasionada pela dificuldade de pulverização de combustível na câmara de combustão em virtude da sua viscosidade.

Quando analisadas em função das diferentes concentrações de biodiesel na mistura, as emissões de monóxido de carbono (CO) sofreram interferência significativa. Desta forma, a Figura 4B permite verificar que a redução nas emissões ocorreu com o aumento do percentual de biodiesel na mistura. Segundo Mazieiro et al. (2006), essas reduções nas emissões específicas de monóxido de carbono podem ser explicadas pela presença de oxigênio na molécula de biodiesel uma vez que a disponibilidade deste comburente na câmara de combustão desloca a reação de queima do combustível no sentido de produzir maiores quantidades de $\mathrm{CO}_{2}$.

A.

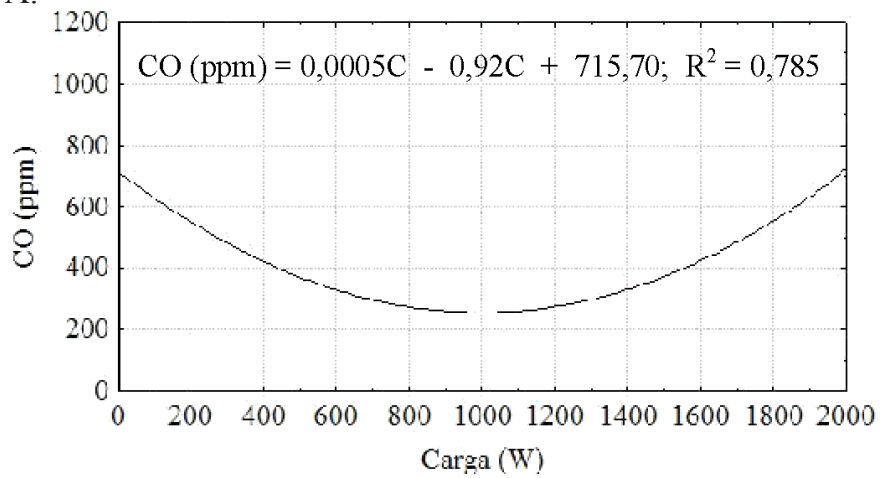

De maneira geral, as emissões de dióxido de carbono $\left(\mathrm{CO}_{2}\right)$ aumentaram em função da ação conjunta da elevação de carga aplicada e do aumento da concentração de biodiesel no combustível, conforme Figura 5.

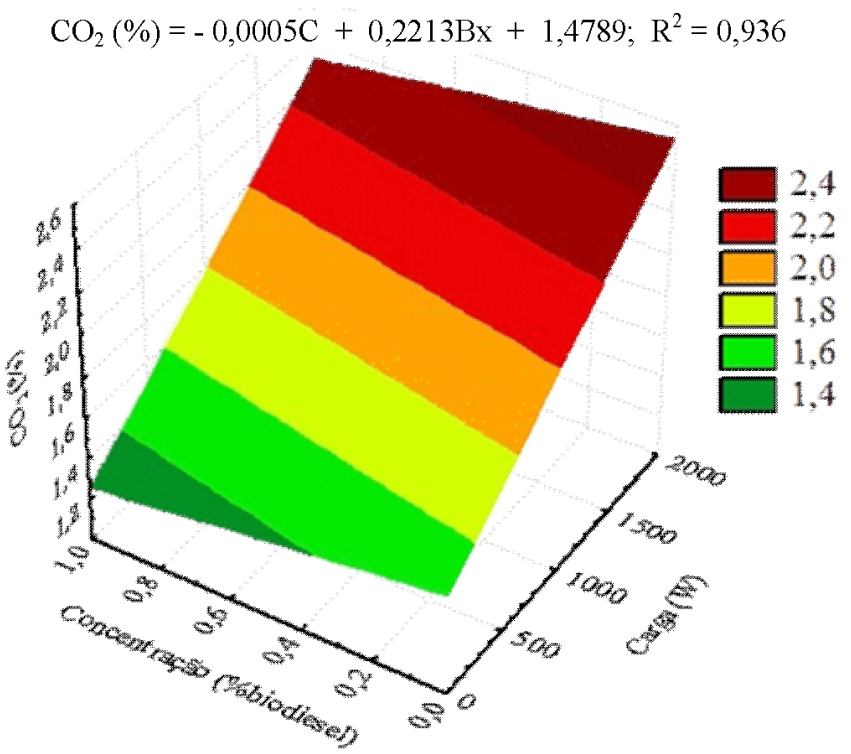

Figura 5. Emissão de dióxido de carbono em função da carga e da concentração de biodiesel

Schumacher et al. (2001) verificaram, estudando as características da emissão de poluentes em testes dinanométricos com motor de compressão utilizando diesel, biodiesel e diferentes misturas de diesel/biodiesel, que a emissão de dióxido de carbono $\left(\mathrm{CO}_{2}\right)$ diminuiu com o aumento da concentração de biodiesel.

Com relação às emissões de óxido de nitrogênio verificouse que as mesmas foram afetadas de forma significativa pelos dois fatores. A partir do modelo obtido foi gerada a superfície de resposta, que representa o efeito dos fatores estudados e, conforme a Figura 6, é possível observar que as emissões de óxidos de nitrogênio aumentaram com a elevação da carga demandada no sistema e o percentual de biodiesel na mistura.

$\mathrm{O}$ aumento efetivo nas emissões se deve principalmente aos pontos de cargas efetivas em que os menores atrasos químicos da combustão do biodiesel facilitam a liberação de calor. Desta maneira, a câmara de combustão atinge valores

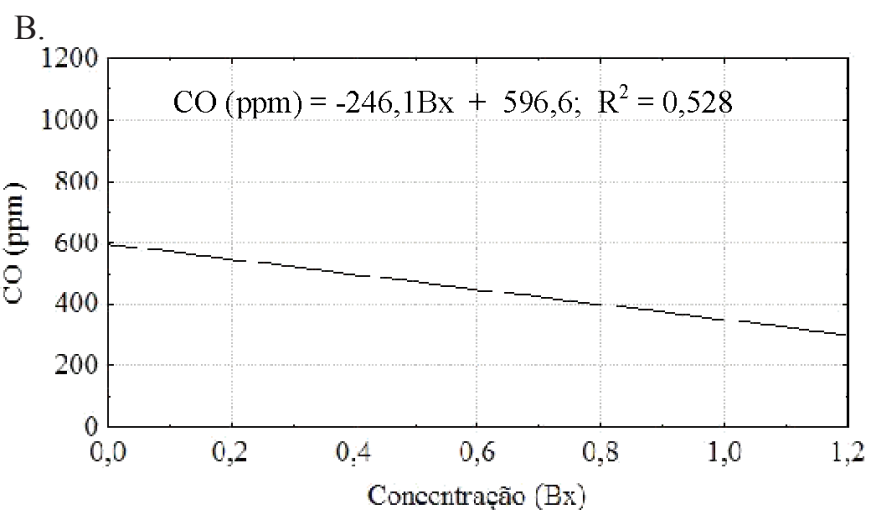

Figura 4. Efeito da carga aplicada no sistema na emissão de $\mathrm{CO}(\mathrm{A})$ e efeito da concentração de biodiesel na mistura nas emissões de $\mathrm{CO}(\mathrm{B})$ 


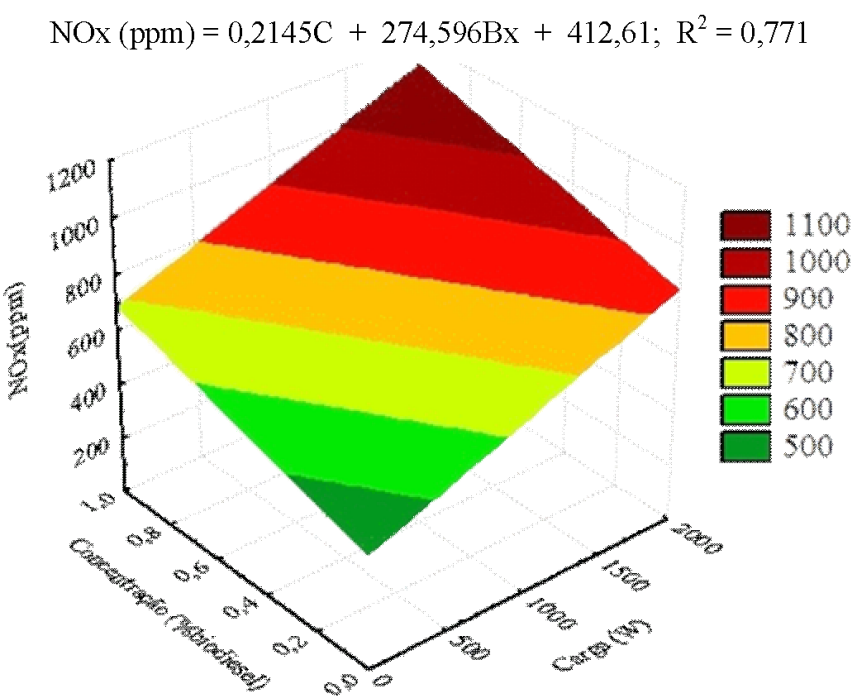

Figura 6. Emissão de óxido de nitrogênio em função da carga e da concentração de biodiesel

maiores de temperatura potencializando a formação de óxidos de nitrogênio. Outro fator que justificaria este aumento quando da utilização de maiores concentrações do biodiesel, seria o alto índice de oxigênio presente na sua estrutura química em razão da sua origem vegetal (Mazieiro et al., 2006).

Krahl (2006) afirma que as emissões de óxido de nitrogênio são aumentadas com a utilização de ésteres, caso a administração do motor não seja alterada, o que é considerado o principal problema junto à emissão de material particulado caracterizando os pontos críticos quando da utilização de biodiesel em motores diesel.

$\mathrm{Na}$ avaliação dos gases emitidos pelos diferentes percentuais de biodiesel e cargas solicitadas no grupo gerador, as emissões de dióxido de enxofre $\left(\mathrm{SO}_{2}\right)$ foram afetadas de forma significativa, pelos dois fatores.

De acordo com a superfície de resposta presente na Figura 7, verificou-se que com o aumento da porcentagem de biodiesel na mistura houve redução nas emissões geradas; em contrapartida, com o aumento da carga aplicada no sistema ocorreu um incremento nas emissões desse gás. Nota-se que houve redução significativa das emissões de dióxido de

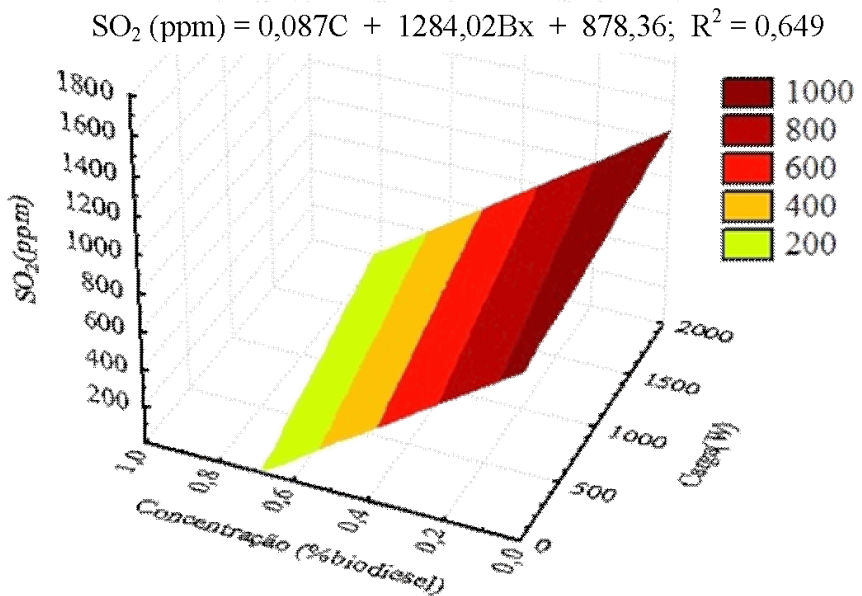

Figura 7. Emissão de dióxido de enxofre em função da carga e da concentração de biodiesel enxofre, em que as mesmas foram praticamente anuladas quando se atingiu a faixa correspondente à concentração de $80 \%$, ou seja, o B 80 .

Resultados semelhantes foram obtidos por Chang et al. (1996) que demonstraram que as emissões de monóxido e dióxido de carbono, dióxido de enxofre e material particulado para o biodiesel, são inferiores às do diesel convencional enquanto os níveis de emissões de gases nitrogenados (NOx) são ligeiramente maiores para o biodiesel.

Desta forma, a ausência de enxofre acaba conferindo, ao biodiesel, uma grande vantagem, pois não há qualquer emissão dos gases de enxofre normalmente detectados no escape dos motores movidos com óleo diesel. Segundo Baik \& Han (2005), o uso de biodiesel como aditivo em substituição aos componentes sulfurosos utilizados, melhora a qualidade do combustível e também permite a redução no conteúdo de enxofre e consequente adequação às rigorosas normas de emissões vigentes.

Com relação aos parâmetros indicadores de desempenho, a avaliação da temperatura é uma das ferramentas que permitem verificar a eficiência no processo de combustão; a Figura 8 representa o efeito da concentração de biodiesel e da carga aplicada na temperatura dos gases de escape. De acordo com a inclinação das retas nota-se um efeito maior da carga aplicada no sistema em relação ao aumento da concentração do biodiesel. Segundo Castellanelli et al. (2008), a maior exigência de potência provoca maior esforço do motor, além de aumento da temperatura dos gases de escape do motor. Os autores citam que efeito contrário ocorre com o aumento da concentração de biodiesel, que acaba provocando redução na temperatura dos gases emitidos.

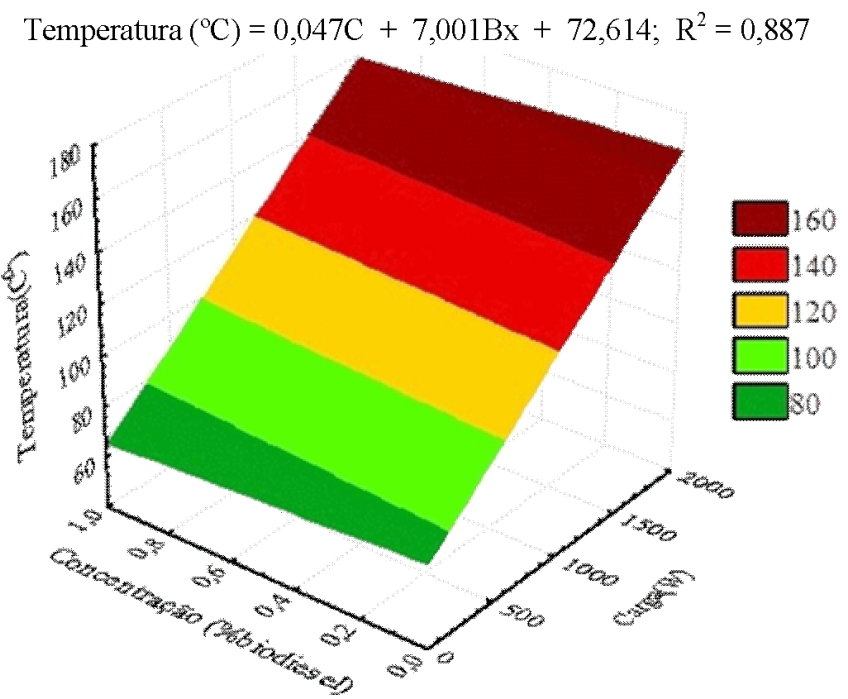

Figura 8. Variação da temperatura dos gases no escape do sistema em função da concentração de biodiesel e da carga demandada

$\mathrm{Na}$ avaliação dos gases emitidos pelos diferentes percentuais de biodiesel e cargas solicitadas no grupo gerador, a eficiência de combustão foi afetada, de forma significativa, pelos dois fatores.

A partir do modelo apresentado foi gerada a superfície apresentada na Figura 9, a qual possibilita verificar que a 
eficiência decresceu quando houve aumento da demanda de carga aplicada pelo sistema. Este fato ocorre principalmente pela mudança de algumas propriedades físicas, como a densidade do combustível em que, segundo Tat et al. (2007), pode haver prejuízos ao sistema de injeção causando anomalias na combustão. Por outro lado, quando a referida superfície é analisada em função do aumento da concentração de biodiesel, é possível verificar um aumento na eficiência de combustão. Segundo Oliveira et al. (2005) referido aumento se deve à maior quantidade de moléculas livres de oxigênio em virtude da adição de álcool ao biodiesel visto que, com uma disponibilidade maior disponibilidade de oxigênio, há maior equilíbrio entre combustível e comburente.

$$
\text { Eficiência }(\%)=-0,005 \mathrm{C}+2,368 \mathrm{Bx}+63,970 ; \mathrm{R}^{2}=0,629
$$

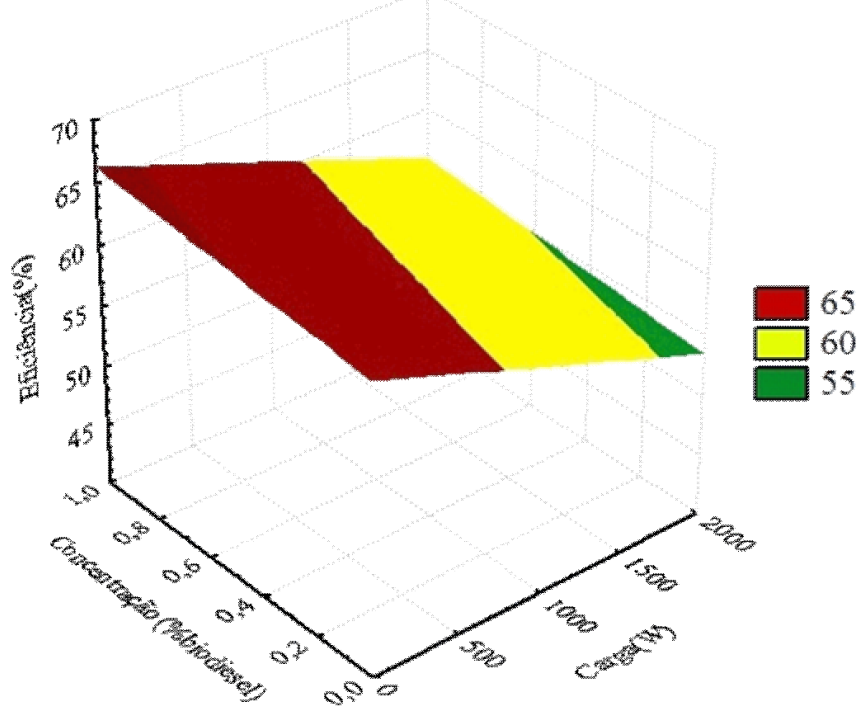

Figura 9. Eficiência de combustão em função da carga e da concentração de biodiesel

\section{Conclusões}

1. Houve aumento no consumo de combustível quando foi aumentada a concentração de biodiesel na mistura e a carga aplicada no sistema.

2. As emissões dos gases $\mathrm{O}_{2}, \mathrm{CO}, \mathrm{SO}_{2}$ e $\mathrm{CO}_{2}$ são maiores quando utilizado o diesel (B5) em relação aos outros combustíveis avaliados. Comportamentos diferentes foram observados com as emissões do óxido de nitrogênio $\left(\mathrm{NO}_{\mathrm{x}}\right)$, que apresentaram maiores valores quando prevalecia $\mathrm{o}$ biodiesel na mistura.

3. As emissões de enxofre decresceram até serem praticamente anuladas quando utilizadas concentrações acima de $80 \%$ de biodiesel na mistura.

4. Verificou-se que, com o aumento da concentração de biodiesel na mistura, ocorreu aumento na eficiência do processo de combustão.

\section{Literatura Citada}

Baik, D. S.; Han, Y. C. The effect of biodiesel and ultra low sulfur diesel fuels on emissions in 11,000 CC heavyduty diesel engine. Journal of Mechanical Science and Technology, v.19, p.870-876, 2005.
Barbosa, R. L.; Silva, F. M.; Salvador, N.; Volpato, C. E. S. Desempenho comparativo de um motor de ciclo diesel utilizando diesel e misturas de biodiesel. Revista Ciência e Agrotecnologia, v.32, p.1588-1593, 2008.

Brasil. Agência Nacional de Petróleo. Resolução n.07, de 19 de março de 2008.

Castellanelli, C. A.; Mayer, F. D.; Castellanelli, M.; Hoffmann, R. Estudo do biodiesel como fonte de energia em geradores diesel no horário de ponta. In: Simpósio de Excelência em Gestão e Tecnologia - SEGeT, 4, 2007. Resende. Anais... Resende: AEDB, 2007. CD-Rom

Castellanelli, M.; Souza, S. N. M.; Silva, S. L.; Kailer, E. K. Desempenho de motor ciclo diesel em bancada dinamométrica utilizando misturas diesel/biodiesel. Engenharia Agrícola, v.28, p.145-153, 2008.

Chang, Y. Z. D.; Gerpen, V. H. J.; Lee, I.; Johnson, A. L.; Hammond, G. E.; Marley, J. S. Fuel properties and emissions of soybean oil esters as diesel fuel. Journal of the American Oil Chemists Society, v.73, p.1549-1555, 1996.

Correa, I. M.; Mazieiro, J. V. G.; Ungaro, M. R.; Bernardi, J. A.; Storino, M. Desempenho de Motor Diesel com Misturas de Biodiesel de Óleo de Girassol. Revista Ciência e Agrotecnologia, v.32, p.923-928, 2008.

Grabosky, M. S., Mccormick, R. L. Combustion of fat and vegetable oil derived fuels in diesel engines. Progress in Energy Combustion Science, v.24, p.125-164, 1998.

Krahl, J. Influência do biodiesel e de diferentes combustíveis diesel sobre as emissões de exaustão e seus efeitos sobre a saúde. In: Knothe, G. (Org.); Gerpen, J. van; Krahl, J. Manual de biodiesel. Tradução: Luiz Pereira Ramos. São Paulo: E. Blücher, 2006. p.193-201.

Mazieiro, J. V. G.; Correa, I. M.; Trielli, M. A.; Bernardi, J. A.; D'agostinho, M. F. Avaliação de emissões poluentes de um motor diesel utilizando biodiesel de girassol como combustível. Engenharia na Agricultura, v.14, p.287-292, 2006.

Miragaya, J. C. G. Biodiesel: Tendências no mundo e no Brasil. Informe Agropecuário, Belo Horizonte, v.26, p.7-13, 2005.

Msipa, C. K. M.; Goering, C. E.; Karcher, T.D. Vegetable oil atomization in a DI diesel engine. Transactions of the ASAE, v.26, p.1669-72, 1983.

Oliveira, E.; Silva, F. M. da; Conde, A. do P.; Barbosa, R. L.; Souza, R. G.; Lima, P. H. G. Desempenho comparativo de motor de combustão alimentado com diesel, B2, B5, B20 e B100. In: Congresso Brasileiro de Plantas Oleaginosas, Óleos, Gorduras e Biodiesel, 2, 2005. Varginha. Anais ... Varginha: UFLA, 2005. p.761-768.

Penteado, R. A. N.; Silva, E. L.; Kruger, E. A.; Rempe, D.; Wilhelm, H. M.; Cunha, R. B. C.; Daemme, L. C.; Bório, H. F.; Laurindo, J. C; Coqueto, J. R. Desempenho de Motores Diesel com o Emprego de Biodiesel, no Acionamento de Grupos Geradores. In: Congresso Brasileiro da Rede de Tecnologia do Biodiesel, 2, 2007, Brasilia. Anais... Brasília: ABIPTI, 2007. CD-Rom

Peres, J. R. R.; Beldrano, N. E. M. Oleaginosas para Biodiesel: Situação e potêncial. In : Ferreira, J. R.; Cristo, C. M. P. N. (coord.). O futuro da indústria: Biodiesel- coletânea de artigos. Brasília: MDIC-STI/IEL, 2006. p.67-82. 
Ramos, L. P.; Kucek, K. T.; Domingos, A. K.; Wilhelm, H. M. Biodiesel: Um projeto de sustentabilidade econômica e sócio-ambiental para o Brasil. Revista Biotecnologia \& Desenvolvimento, v.31, p.28-37. 2003.

Romero, J.; Miralles, J. Biocombustibles perspectiva ambiental. Barcelona: Associoacion de Mestres Rosa Sensat. Fundacion Terra, v.24, 2002.34p.

Schumacher, L. G.; Marshall, W.; Krahl, J.; Wetherel W. B.; Grabowski M. S. Biodiesel emissions data from series 60 DDC Engines. Transaction of the ASAE. v.44, p.14651468, 2001.

Silva, F. N.; Prata, A. S.; Teixeira, J. R. Technical feasibility assessment of oleic sunflower methyl ester utilization in diesel bus engine, Energy Conversion \& Management, v.44, p.2347-2365, 2003.
Silva, M. J.; Souza, S. N. M.; Souza, A. A.; Martins, G. I.; Secco, D. Motor gerador ciclo diesel sob cinco proporções de biodiesel com óleo diesel. Revista Brasileira de Engenharia Agrícola e Ambiental, v.16, p.320-326, 2012.

Soranso, A. M.; Gabriel Filho, A.; Lopes, A.; Souza, E. G.; Dabdoub, M. J.; Furlani, C. E. A.; Camara, F. T. Desempenho dinâmico de um trator agrícola utilizando biodiesel etílico destilado de óleo residual. Revista Brasileira de Engenharia Agrícola e Ambiental, v.12, p.553-559, 2008.

Tat, M. E.; Gerpen, J. H. van; Wang, P. S. Fuel property effects on injection timing, ignition timing, and oxides of nitrogen emissions from biodiesel-fueled engines. Transaction of the ASABE, v.50, p.1123-1128, 2007.

Xue, J.; Grift, T. E.; Hansen, A. C. Effect of biodiesel on engine performances and emissions. Renewable and Sustainable Energy Reviews, v.15, p.1098-1116, 2011. 